\title{
A Plasticity Criterion for Mixed Mode Fracture Initiation with Crack Surface Frictional Characteristics Under Compression
}

\author{
J.W. Zhou* ${ }^{* 1,2}$, X.G. Yang ${ }^{2}$, H.T. Li ${ }^{2}$ and H.W. Zhou ${ }^{2}$ \\ ${ }^{1}$ Key Laboratory of Mountain Hazards and Surface Process, Chinese Academy of Sciences, Chengdu 610044, China \\ ${ }^{2}$ State Key Laboratory of Hydraulics and Mountain River Engineering, Sichuan University, Chengdu 610065, China
}

\begin{abstract}
A new plasticity criterion for mixed mode crack initiation angles under compression is presented, based on the characteristics of the plastic core region surrounding the crack tip with crack surface friction. The shape and size of the plastic core region were thoroughly analyzed under compression and the non-dimensional variable radius of the plastic core region for mixed mode compressive fracture was considered. Obviously, the mixed mode fracture initiation under compression is influenced by the frictional characteristics of the crack surface and the external compressive loading state. The loading ratio, Poisson's ratio and the influence of the friction coefficient on the crack tip plastic radius were analyzed. The proposed criterion shows that the crack extends in the direction of the global minimum of the plastic core region boundary. The presented criterion was simulated for various compressive loads and was compared, with other available criteria, against the laboratory experimental data. It can be seen that the presented criterion provides a better agreement with the experimental data.
\end{abstract}

Keywords: Crack tip plasticity, mixed mode fracture, crack propagation, stress intensity factors, friction.

\section{INTRODUCTION}

Crack initiation under tension has been extensively investigated, both analytically and experimentally $[1,2]$. However, relatively little research has been undertaken into crack initiation under compression. In order to accurately predict and simulate crack propagation paths under compression, one must define a valid criterion for the crack initiation angle [3-5]. The crack will propagate forming wing cracks under compression [6]. As crack slip under shear stress and the slip itself cause wing cracks to grow at the crack tip, the study of mixed mode fracture initiation under compression is very important [7].

The sliding crack mechanism, first introduced by Brace and Bombolakis [8], is often considered in the literature and is used as a starting point for further investigations of cracking under compression [9-11]. The crack is closed and the crack surface is subjected to normal compression and friction, which significantly affects the crack stress intensity factor, as the closed crack has frictional and cohesive resistance $[12,13]$. The assumption that is made about the frictional resistance of the crack is very important for calculating the value of the crack initiation angle under compression. The stress state at the crack tip is very complicated under compression and there is a plastic core region. Crack propagation will occur when the fracture energy reaches a certain value [14-18].

The main objective of this study was to present a plasticity criterion for mixed mode fracture initiation when the crack surface friction is under compression. Key issues

*Address correspondence to this author at the Key Laboratory of Mountain Hazards and Surface Process, Chinese Academy of Sciences, Chengdu 610044, China; Tel: +86 28 85405011; Fax: +86 28 85402897;

E-mail: jwzhou@scu.edu.cn include: the plastic core region, the stress intensity factor at the crack tip, the crack friction, and the minimum fracture energy. The remainder of the paper is organized as follows. In Section 2, a plasticity criterion for mixed mode fracture initiation under compression is presented. In Section 3, the plastic core region and crack initiation angle under different compression conditions are illustrated. In Section 4, the effects of the crack friction coefficient are discussed. Conclusions are presented in Section 5.

\section{PLASTIC CRITERION FOR MIXED MODE FRACTURE INITIATION UNDER COMPRESSION}

In this section, the definition of the radius of the plastic core region, based on the crack tip elastic stresses, is illustrated first. A plasticity criterion for the crack initiation angle is established, based on the crack propagation that will occur when the fracture energy is at a minimum. Finally, a computational method for determining the stress intensity factors at the crack tip is established.

\subsection{Plastic Criterion for Mixed Mode Fracture}

As the existing research data shows that the stress state at the crack tip is very complicated, some simplifying assumptions are usually made. Fig. (1) shows the elastic-plastic stress state at the crack tip. There is a plastic region surrounding the crack tip.

As shown in Fig. (1), $r$ is the radius of the plastic core region, and $\theta$ is the crack initiation angle. Fig. (1a) shows the definition of the polar coordinate for plane cracking. For a crack under mixed mode condition, the linear elastic stress field at the crack tip under compression can be expressed as follows (plane strain problem) [1]: 
(a)
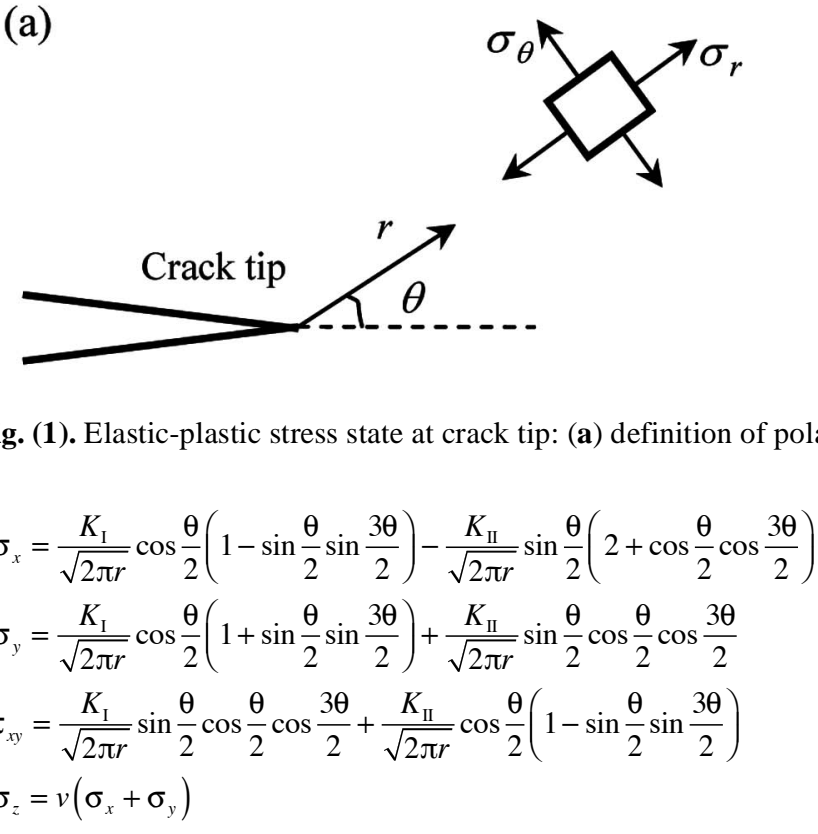

where $\sigma_{x}, \sigma_{y}, \sigma_{z}$ and $\tau_{x y}$ are the stresses at the crack tip; $\theta$ and $r$ are the angle and distance of special point to the crack tip, respectively; $v$ is Poisson's ratio; $K_{\mathrm{I}}$ and $K_{\mathrm{II}}$ are the stress intensity factors of type I and type II cracks, respectively.

As shown in Fig. (1b), there is a plastic region around the crack tip and crack propagation will occur along with the minimum elastic fracture energy. For plane strain, the minimum $J_{2}$ yield function is used to define the variable radius of the plastic core region [3],

$J_{2}=\frac{1}{6}\left[\left(\sigma_{x}-\sigma_{y}\right)^{2}+\left(\sigma_{y}-\sigma_{z}\right)^{2}+\left(\sigma_{z}-\sigma_{x}\right)^{2}\right]+\tau_{x y}^{2}$

where $J_{2}$ is the second invariant variable of the stress deviation.

For a crack of length $2 c$ and a crack inclination angle of $\varphi$, in general, the stress intensity factor at the crack tip can be expressed as follows:

$$
K_{\mathrm{i}}=\sigma \sqrt{\pi c} f_{K_{\mathrm{i}}}(\varphi)
$$

where, $i=\mathrm{I}$ is the type I crack; $i=\mathrm{II}$ is the type II crack; and $f_{K_{\mathrm{i}}}(\varphi)$ is the function of $\varphi$.

For a crack under uniaxial compression, the function $f_{K_{\mathrm{i}}}(\varphi)$ can be expressed as follows:

$\left\{\begin{array}{l}f_{K_{1}}(\varphi, \mu)=\cos ^{2} \varphi \\ f_{K_{\mathrm{II}}}(\varphi, \mu)=\sin \varphi \cos \varphi-\mu \cos ^{2} \varphi\end{array}\right.$

For a crack under biaxial compression, the function $f_{K_{\mathrm{i}}}(\varphi)$ can be expressed as follows:

$\left\{\begin{array}{l}f_{K_{\mathrm{I}}}(\varphi, \mu, \lambda)=\cos ^{2} \varphi+\lambda \sin ^{2} \varphi \\ f_{K_{\mathrm{II}}}(\varphi, \mu, \lambda)=(1-\lambda) \sin \varphi \cos \varphi-\mu\left(\cos ^{2} \varphi+\lambda \sin ^{2} \varphi\right)\end{array}\right.$ (b)

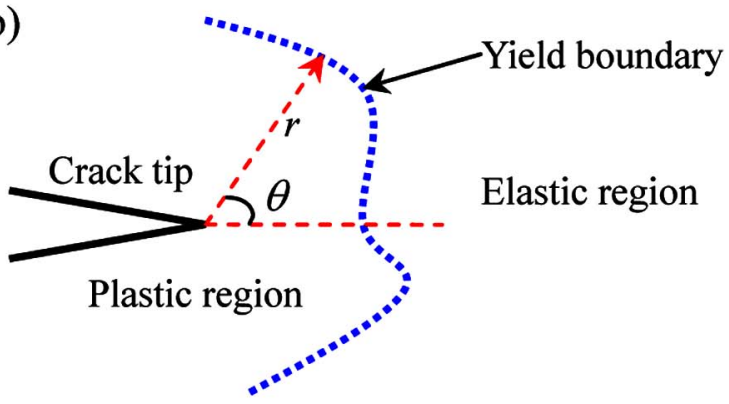

where $\varphi$ is the crack inclination angle; $\mu$ is the crack friction coefficient; and $\lambda$ is the loading ratio for biaxial compression (details of the definition are given below).

For plane strain, the radius function of the plastic core region is defined as follows:

$R_{\mathrm{P}}\left(\theta, f_{K_{\mathrm{i}}}\right)=\frac{r_{\mathrm{P}}\left(\theta, f_{K_{\mathrm{i}}}\right)}{c\left(\frac{\sigma}{\sqrt{3 J_{2}}}\right)^{2}}=f_{K_{\mathrm{I}}}^{2}(\varphi)\left(g_{1}(\theta)+h_{1}(\theta, v)\right)+$

$f_{K_{\mathrm{II}}}^{2}(\varphi)\left(g_{2}(\theta)+h_{2}(\theta, v)\right)+f_{K_{1}}(\varphi) f_{K_{\mathrm{II}}}(\varphi)\left(g_{12}(\theta)+h_{12}(\theta, v)\right)$

where $g_{1}(\theta)=\frac{7+4 \cos \theta-3 \cos 2 \theta}{16} ; \quad g_{2}(\theta)=\frac{19-4 \cos \theta+9 \cos 2 \theta}{16}$; $g_{12}(\theta)=\frac{-2 \sin \theta+3 \sin 2 \theta}{4} ; \quad h_{1}(\theta, v)=v(v-1)(1+\cos \theta) ;$ $h_{2}(\theta, v)=v(v-1)(1-\cos \theta)$; and $h_{12}(\theta, v)=-2 v(v-1) \sin \theta$.

In the plastic core region, crack propagation will occur when the fracture energy is at a minimum. For the crack initiation angle, it is assumed that the minimum angle which will allow the plastic core radius to form is,

$R_{\mathrm{P}}\left(\theta_{0}, f_{K_{\mathrm{i}}}\right)=\min \left\{R_{\mathrm{P}}\left(\theta, f_{K_{\mathrm{i}}}\right)\right\}, \theta=\left[\begin{array}{ll}-180^{\circ} & 180^{\circ}\end{array}\right]$

where $\theta_{0}$ is the crack initiation angle.

Mathematically, the plastic criterion can be stated as [5],

$\frac{\partial R_{\mathrm{P}}}{\partial \theta}=0 \quad$ and $\quad \frac{\partial^{2} R_{\mathrm{P}}}{\partial \theta^{2}}>0$

The crack initiation angle can then be obtained by combining Eqs. (6)-(8).

\subsection{Stress Intensity Factor at the Crack Tip}

Two loading conditions are considered for a compressive-shear crack: (a) uniaxial compression, and (b) biaxial compression (see Fig. 2).

When the crack is under uniaxial compression, the normal stress $\sigma$ and shear stress $\tau$ in the crack surface are,

$\left\{\begin{array}{l}\sigma=\sigma_{11} \cos ^{2} \varphi \\ \tau=\sigma_{11} \sin \varphi \cos \varphi\end{array}\right.$

The friction characteristics of the crack surface are considered, and the cohesion of the crack surface is assumed to be equal to 0 , then 
(a)

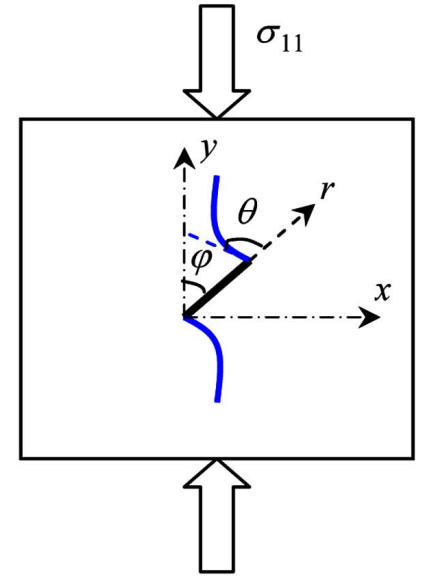

(b)

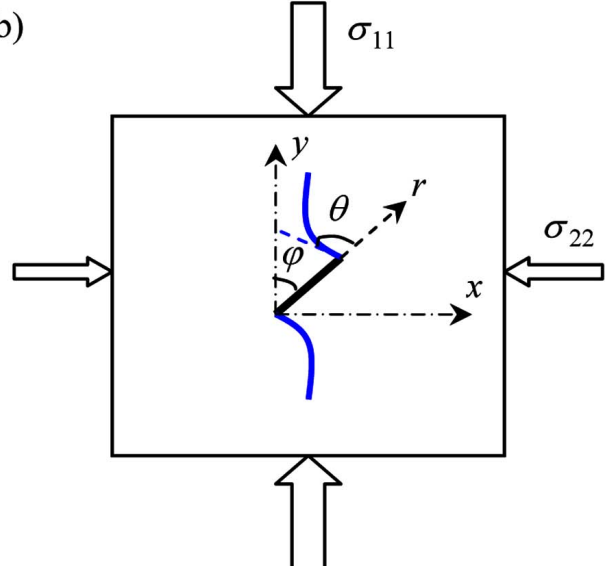

Fig. (2). Compressive-shear cracking under different compression conditions: (a) uniaxial compression; and (b) biaxial compression.

$\tau^{e f f}=\sigma_{11} \sin \varphi \cos \varphi-\mu \sigma_{11} \cos ^{2} \varphi$

The stress intensity factors at the crack tip under uniaxial compression are,

$\left\{\begin{array}{l}K_{\mathrm{I}}=\sigma_{11} \cos ^{2} \varphi \sqrt{\pi c} \\ K_{\mathrm{II}}=\left(\sigma_{11} \sin \varphi \cos \varphi-\mu \sigma_{11} \cos ^{2} \varphi\right) \sqrt{\pi c}\end{array}\right.$

When the crack is under biaxial compression, the normal stress $\sigma$ and shear stress $\tau$ in the crack surface are,

$\left\{\begin{array}{l}\sigma=\sigma_{11} \cos ^{2} \varphi+\sigma_{22} \sin ^{2} \varphi \\ \tau=\left(\sigma_{11}-\sigma_{22}\right) \sin \varphi \cos \varphi\end{array}\right.$

The friction characteristics of the crack surface are considered, and the cohesion of the crack surface is assumed to be equal to 0 ,

$\tau^{e f f}=\left(\sigma_{11}-\sigma_{22}\right) \sin \varphi \cos \varphi-\mu\left(\sigma_{11} \cos ^{2} \varphi+\sigma_{22} \sin ^{2} \varphi\right)$

The loading ration for biaxial compression is defined as,

$\lambda=\sigma_{22} / \sigma_{11}$

The stress intensity factors at the crack tip under biaxial compression are then,

$$
\left\{\begin{array}{l}
K_{\mathrm{I}}=\sigma_{11}\left(\cos ^{2} \varphi+\lambda \sin ^{2} \varphi\right) \sqrt{\pi c} \\
K_{\mathrm{II}}=\left(\sigma_{11}(1-\lambda) \sin \varphi \cos \varphi-\mu \sigma_{11}\left(\cos ^{2} \varphi+\lambda \sin ^{2} \varphi\right)\right) \sqrt{\pi c}
\end{array}\right.
$$

Once the stress intensity factors at the crack tip under different compression conditions have been obtained, then the radius of the plastic core region can be calculated.

\section{PLASTIC CORE REGION AND CRACK INITIA- TION ANGLE UNDER DIFFERENT COMPRESSION CONDITIONS}

In this section, the plastic core region and crack initiation angle under different compression conditions are illustrated. Two loading conditions are considered: (a) uniaxial compression, and (b) biaxial compression. The crack initiation angle under biaxial compression is obviously influenced by the crack surface friction, and the crack surface friction is influenced by the loading ratio, which is the confining stress divided by the axial stress.

\subsection{Uniaxial Compression}

Fig. (3a) shows the sensitivity analysis for Poisson's ratio, when the crack inclination angle is $30^{\circ}$ and the crack friction coefficient is 0.3 . Fig. (3b) shows the sensitivity analysis for the crack friction coefficient, when the crack
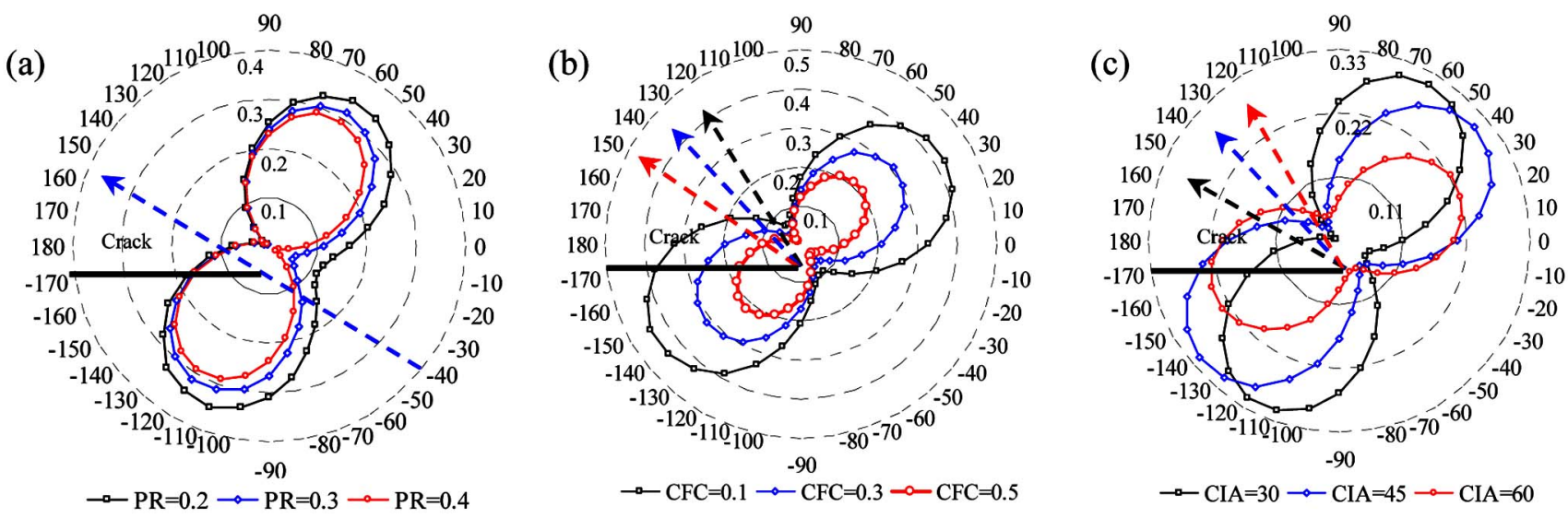

Fig. (3). Plastic core region and CIA under uniaxial compression: (a) sensitivity analysis of PR; (b) sensitivity analysis of CFC; and (c) sensitivity analysis of CIA. Key: $\mathrm{CFC}=$ crack friction coefficient; $\mathrm{CIA}=$ crack initiation angle; $\mathrm{PR}=$ Poisson's ratio. 
inclination angle is $45^{\circ}$ and Poisson's ratio is 0.3. Fig. (3c) shows the sensitivity analysis for the crack inclination angle, when the crack friction coefficient is 0.3 and Poisson's ratio is 0.3 .

As shown in Fig. (3a), the extent of the plastic core region will decrease as Poisson's ratio increases, but the crack initiation angle is not influenced by Poisson's ratio, it is fixed at $150^{\circ}$. As shown in Fig. (3b), the size of the plastic core region will decrease rapidly as the crack friction coefficient increases, thus the crack surface friction will prevent the crack propagating. The crack initiation angle will increase as the crack friction coefficient increases. The crack initiation angles are $120^{\circ}, 130^{\circ}$, and $140^{\circ}$ when the crack friction coefficient is equal to $0.1,0.3$, and 0.5 , respectively. As shown in Fig. (3c), the plastic core region will decrease in size as the crack inclination angle increases. Thus, fracture will occur when the direction of the crack is parallel to the axial stress. The crack initiation angle will decrease as the crack inclination angle increases, the crack initiation angles are $150^{\circ}, 130^{\circ}$, and $110^{\circ}$ when the crack inclination angles are $30^{\circ}, 45^{\circ}$, and $60^{\circ}$, respectively.

\subsection{Biaxial Compression}

Fig. (4a) shows the sensitivity analysis of Poisson's ratio, when the crack inclination angle is $45^{\circ}$, the crack friction coefficient is 0.2 and the loading ratio for biaxial compression is 0.5 . Fig. (4b) shows the sensitivity analysis of the loading ratio for biaxial compression, when the crack inclination angle is $45^{\circ}$, Poisson's ratio is 0.3 , and the crack friction coefficient is 0.2 .

As shown in Fig. (4a), the manner in which the plastic core region and the crack initiation angle vary under biaxial compression is similar to that for uniaxial compression. The crack initiation angle is fixed at $170^{\circ}$. But because of the lateral stress, the radius of the plastic core region is less under uniaxial compression. Thus, it is harder for the crack to fracture under biaxial compression. As shown in Fig. (4b), the size of the plastic core region changes rapidly along with the increase of loading ratio for biaxial compression. Crack initiation angles are $130^{\circ}, 170^{\circ}$, and $-160^{\circ}$ when the loading ratios are $0.0,0.5$ and 1.0 , respectively. The computed results show that the crack initiation angle is clearly influenced by the loading ratio.

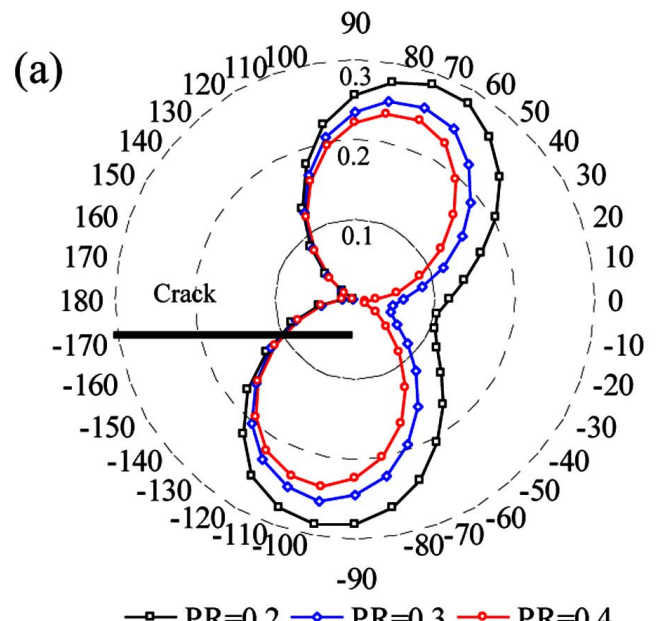

Fig. (5a) shows the sensitivity analysis for the crack friction coefficient, when the crack inclination angle is $45^{\circ}$, Poisson's ratio is 0.3 and the loading ratio for biaxial compression is 0.5 . Fig. (5b) shows the sensitivity analysis of the crack inclination angle, when the crack friction coefficient is 0.3 , Poisson's ratio is 0.3 , and the loading ratio for biaxial compression is 0.5 .

As shown in Fig. (5a), it is clear that the extent of the plastic core region will change as the crack friction coefficient increases. This means that the crack propagation will be influenced by the crack surface friction. The crack initiation angle will increase as the crack friction coefficient increases, the crack initiation angles are $160^{\circ}, 180^{\circ}$, and $-160^{\circ}$ when the crack friction coefficient equals $0.1,0.3$, and 0.5 , respectively. As shown in Fig. (5b), the extent of the plastic core region will decrease as the crack inclination angle increases. This means that fracture will occur when the direction of the crack is parallel to the axial stress. The crack initiation angle will decrease as the crack inclination angle increases. The crack initiation angles are $170^{\circ}, 160^{\circ}$, and $150^{\circ}$ when the crack inclination angles are $30^{\circ}, 45^{\circ}$, and $60^{\circ}$, respectively.

\section{EFFECTS OF CRACK FRICTION COEFFICIENT AND CONFINING STRESS}

In Section 3, the computed results showed that the crack initiation angles predicted by the plastic criterion do not depend on Poisson's ratio, and also for most of other fracture criterion, such as the maximum tangential stress criterion (MTS criterion) and the maximum triaxial stress criterion (T criterion). For a crack under compression, the crack initiation angle is influenced by the crack closure effect, which is equivalent to the crack friction function based on the MohrCoulomb criterion. And for a crack under biaxial compression, the plastic core region and crack initiation angle are influenced by the loading ratio for biaxial compression, the crack propagation will be limited by the lateral stress. Crack propagation under compression is influenced by the loading patterns and crack frictional characteristics.

Fig. (6a) shows the crack initiation angle predicted by the MTS criterion, $\mathrm{T}$ criterion and plastic criterion under uniaxial compression compared with the experimental data

(b)

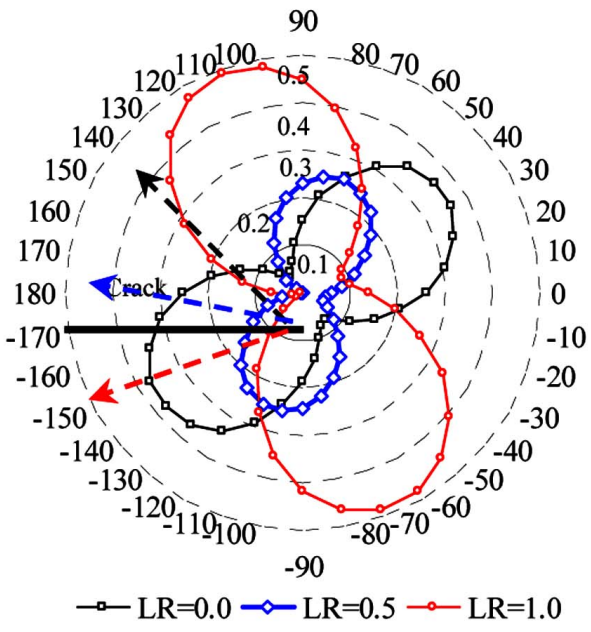

Fig. (4). Plastic core region and crack initiation angle under biaxial compression: (a) sensitivity analysis of PR; and (b) sensitivity analysis of loading ratio (LR) of biaxial compression (see key in Fig. 3 for symbols). 
(a)

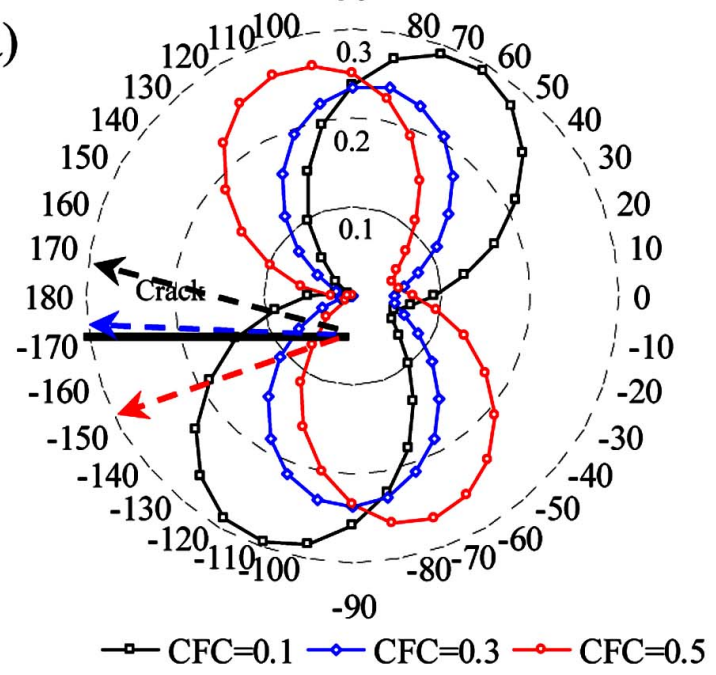

(b)

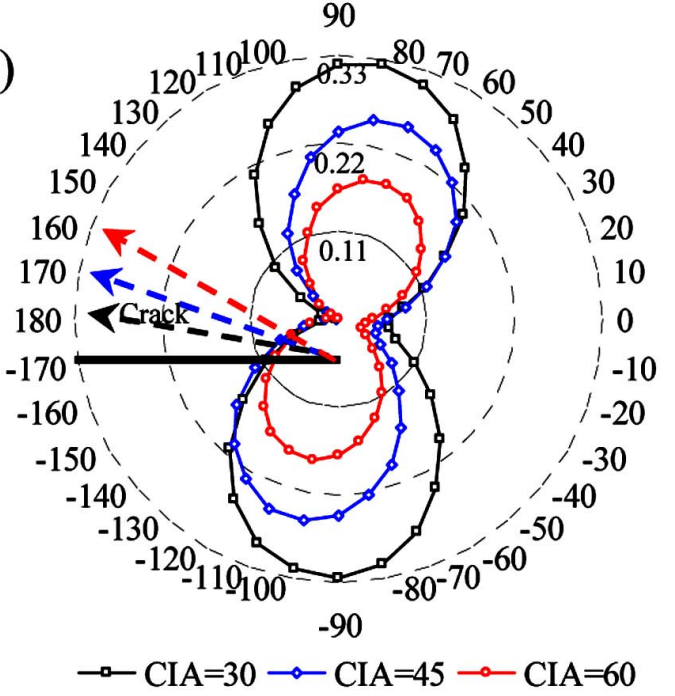

Fig. (5). Plastic core region and crack initiation angle under biaxial compression: (a) sensitivity analysis of CFC; and (b) sensitivity analysis of CIA (see key in Fig. 3 for symbols).
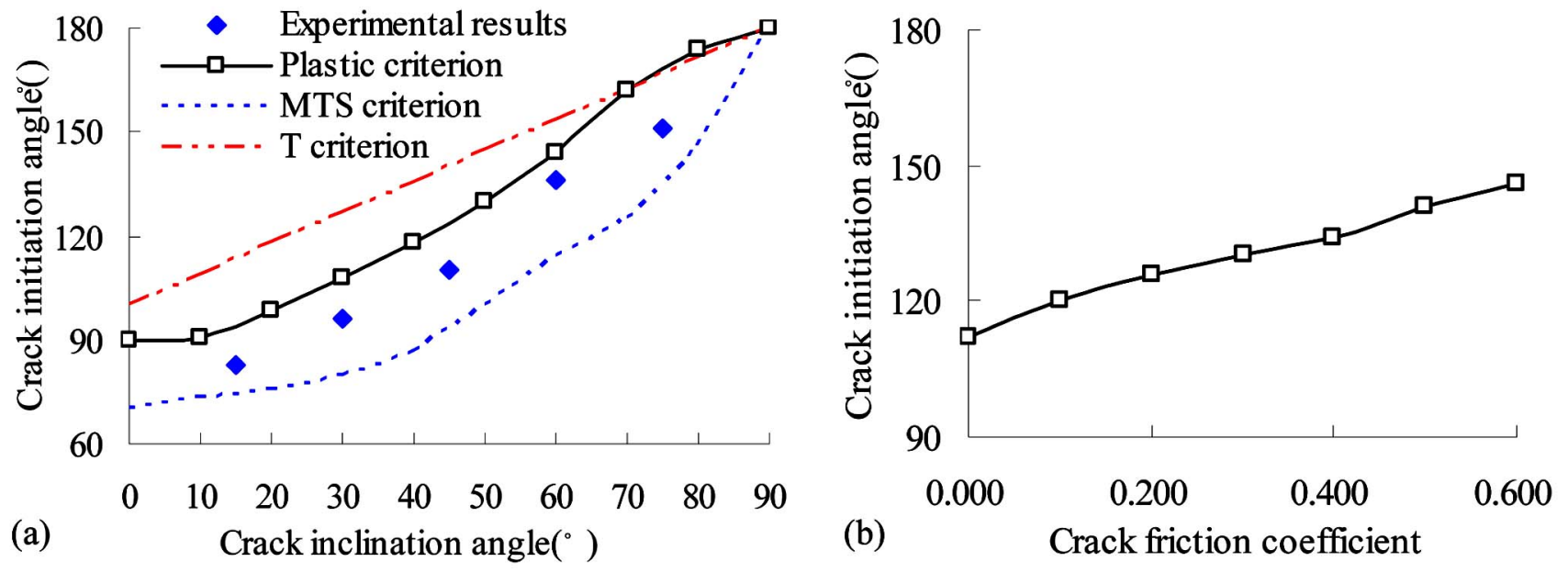

Fig. (6). Crack initiation angle under uniaxial compression: (a) different fracture criteria and crack inclination angles; and (b) relationship between crack initiation angle and crack friction coefficient.

by Vallejo [19, 20]. Fig. (6b) shows the relationship between the crack initiation angle and the crack friction coefficient under uniaxial compression.

As shown in Fig. (6a), the plastic criterion and MTS criterion provide the closest fit to the experimental data under uniaxial compression, but the MTS criterion does not agree with the experimental data. As shown in Fig. (6b), the crack initiation angle is obviously influenced by the crack friction coefficient; it increases as the crack friction coefficient increases while the other parameters remain constant.

Fig. (7) shows the relationship between the crack initiation angle and the loading ratio under biaxial compression.

As shown in Fig. (7), the lateral stress is tensile when the loading ratio is negative, and the lateral stress is compressive when the loading ratio is positive. The computed results show that the crack initiation angle increases with the loading ratio.

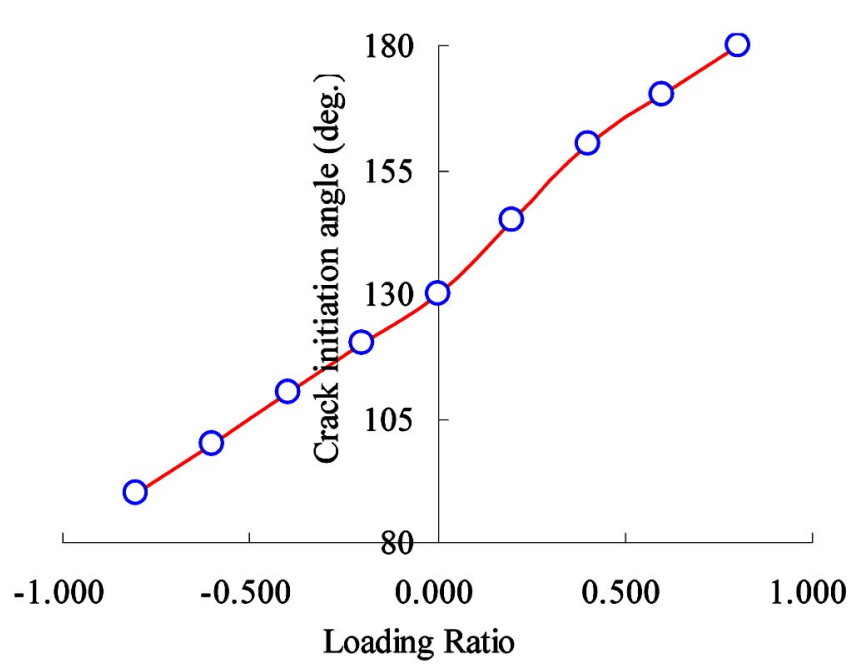

Fig. (7). Crack initiation angle under different biaxial compressions. 


\section{CONCLUSIONS}

A plasticity criterion for mixed mode fracture initiation with crack surface frictional characteristics under compression has been presented. The criterion incorporates the plastic core region at the crack tip, the stress intensity factors of type I and type II cracks, and the minimum fracture energy for fracture initiation. It was assumed that the elastic stress state at the crack tip was linear. The crack surface frictional characteristics for the stress intensity factors of type I and type II cracks were considered. During cracking under compressive loading, crack propagation occurs when the fracture energy reaches a minimum value. The plastic core region and crack initiation angle under different compression conditions show that, the crack initiation angle is influenced by the crack friction coefficient and loading ratio for biaxial compression, but is not influenced by Poisson's ratio. The validity of the plastic criterion for mixed mode fracture initiation under compression was confirmed by comparing the numerical predictions and experimental data. The crack initiation angle under compression was in good agreement with the experimental data. The plastic criterion can be used to predict the crack initiation angle for the mixed model crack under compression.

\section{ACKNOWLEDGEMENTS}

The support of the Chinese National Natural Science Foundation (Grant No. 41030742 and No. 40972190) and the Sichuan University Youth Foundation (Grant No. 2008047) are gratefully acknowledged.

\section{REFERENCES}

[1] Anderson TL. Fracture Mechanics: Fundamentals and Applications. $2^{\text {nd }}$ ed. New York: CRC Press 1995.

[2] Irwin GR. Fracture dynamics. fracturing of metals. American Society for Metals: Cleveland, Ohio; 1948.

[3] Swartz SE, Taha NM. Mixed mode crack propagation and fracture in concrete. Eng Fract Mech 1990; 37: 171-80.

[4] Endo M, Sakai H, Mcevily AJ. An analysis of mode I fatigue crack growth under biaxial stress. Int J Mod Phys B 2006; 20: 3824-29.
[5] Yamakawa M, Hashimoto C, Watanable T, Yokote S. Study on settlement crack for reinforced concrete structures using the concrete with Type IV fly ash. Int J Mod Phys B 2003; 17: 1470-5.

[6] Ukadgaonker VG, Awasare PJ. A new criterion for fracture initiation. Eng Fract Mech 1995; 51: 265-74.

[7] Ranganathan N, Jendoubi K, Merah N. Experimental characterization of the elastic-plastic strain fields at the crack tip due to cycling loading. J Eng Mater Technol 1994; 116: 187-202.

[8] Brace W, Bombolakis E. A note on brittle crack growth in compression. J Geophys Res 1963; 68: 3709-13.

[9] Khan SMA, Khraisheh MK. Analysis of mixed mode crack initiation angles under various loading conditions. Eng Fract Mech 2000; 67: 397-419.

[10] Bjerke T, Li Z, Lambros J. Role of plasticity in heat generation during high rate deformation and fracture of polycarbonate. Int $\mathrm{J}$ Plasticity 2002; 18: 549-67.

[11] Chang KH, Lee CH. J-integral for 3-D interface crack configuration in welds of dissimilar steels. Int J Mod Phys B 2006; 20: 42016.

[12] Nishioka T, Tokudome H, Kinoshita M. Dynamic fracture-path prediction in impact fracture phenomena using moving finite element method based on Delaunay automatic mesh generation. Int $\mathbf{J}$ Solids Struct 2001; 38: 5273-301.

[13] Lauterbach B, Gross D. Crack growth in brittle solids under compression. Mech Mater 1998; 29: 81-92.

[14] Gross D, Heimer S. Crack closure and crack path prediction for curved cracks under thermal load. Eng Fract Mech 1993; 46: 63340 .

[15] Sahouryeh E, Dyskin AV, Germanovich LN. Crack growth under biaxial compression. Eng Fract Mech 2002; 69: 2187-98.

[16] Lee S, Ravichandran G. Crack initiation in brittle solids under multiaxial compression. Eng Fract Mech 2003; 70: 1645-58.

[17] Gorbatikh L, Nuller B, Kachanov M. Sliding on cracks with nonuniform frictional characteristics. Int J Solids Struct 2001; 38: 7501-24.

[18] Rahman M, Hancock JW. Elastic perfectly-plastic asymptotic mixed mode crack tip fields in plane stress. Int J Solids Struct 2006; 43: 3692-704.

[19] Vallejo LE. The brittle and ductile behavior of a material containing a crack under mixed-mode loading. In: 28th US Symposium on Rock Mechanics, Tucson 29 June-1 July 1987; pp. 383-390.

[20] Theocaris PS, Andrianopoulos NP. The Mises elastic-plastic boundary as the core region in fracture criteria. Eng Fract Mech 1982; 16: 425-32.

This is an open access article licensed under the terms of the Creative Commons Attribution Non-Commercial License (http://creativecommons.org/licenses/by-nc/3.0/) which permits unrestricted, non-commercial use, distribution and reproduction in any medium, provided the work is properly cited. 